\title{
Psycho-Social Attributes of Male Volleyball Players in Kenya
}

\author{
ELIJAH G. RINTAUGU ${ }^{1}$ NICHOLAS K.BAILASHA ${ }^{2} \quad$ MICHAEL OTIENO $^{2}$ \\ 1.Department of Recreation and Sport Management ,Kenyatta University ,Nairobi ,Kenya \\ 2. Department of Physical Education and Sport, University of Nairobi ,Kenya
}

\begin{abstract}
Socialization into sport revolves around initial entry, continued participation and seeking excellence. Kenyan women volleyball players have returned significant successes at regional and continental competitions.However their success is not comparable to men teams which are yet to set any accolades at regional and continental level. The purpose of this study was to investigate pyscho-social attributes of Kenya male volleyball players who took part Kenya Volleyball Federation (KVF) league in 2015.The attributes investigated involved family background factors, reasons for specialization and motivesforcontinued participation.Data was collected through self-reported questionnaires from $(\mathrm{n}=71)$ participants and was analyzed for frequencies and percentages. Results indicated majority of $38.5 \%$ had experiences of one to three years, majority of them (over $50 \%$ ) came from lower and middle class backgrounds, reasons for specialization were; talent, enjoyment and social interactionswhilethe motives for continued participation were talent, desire to win and success in volleyball. It is concluded that male volleyball players entry into volleyball and their continued participation is buttressed in intrinsic motives. Consequently, coaches and team managers need to take stock of these drivers of seeking excellence in volleyball. Future studies need to be conducted to unearth the relationship between socio-psychological factors and technical and tactical shortfalls of the men volleyball players in Kenya.
\end{abstract}

Keywords: Volleyball, Kenya Volleyball Federation (KVF), Social Economic Status (SES)

DOI: $10.7176 / \mathrm{JTHS} / 50-06$

Publication date:September $30^{\text {th }} 2020$

\section{Introduction}

Career orientation and paths of an elite athlete is shaped by socialization process in which socialization agents, social-cultural influences, socializing situations, the self and environment have significant roles to play (Stevenson, 1990; Philips, 1993, Rintaugu, 2005). However, the socialization process is dynamic and the social interactions and influence change from one level of involvement to the other. Socialization into sport refers to the initial involvement, continued participation and seeking for excellence (Coakley, 2005, Rintaugu, 2009). At all levels of sport involvement, different socializing agents such as significant others(parents, family, peers, friends), socializing situations (school, media, community agencies) and environment play crucial roles to sustain participation (Mcpherson,Loy, \& Kurtis,1989 ;Coakley,2005 ;Rintaugu,2005 )

Sociological studies reveal that for athletic ability to translate into sustained good performance, athletes must get support and encouragement from significant others (Ipinmoroti \& Ajayi, 2003; Rintaugu,2005; Rintaugu, 2009). Significant others transmit attitudes and values about sport, pay activity fees, provide role modeling , provide physical and emotional support, encourage, and reward about sport participation. Beyond the family, athletes have play partners(peers, friends) from the neighbourhood while teachers and coaches are instrumental in technical instruction and evaluation of performance (Rintaugu, 2009;Kubayi ,Jooste ,Toriola et al.,2014; Otieno ,Bailasha \& Rintaugu ,2020). This happens in the confines of the schools and community agencies such as sport clubs and religious sport outfits. The role of secondary school in socialization into sport in Kenya reveals that some games are encultured and domiciled in selected school where their dominance and legacy has transcended many generations (Wamukoya ,1994;Rintaugu ,2005).

Several psycho-social theories have been peddled to understand socialization into sport.Some of the theories include self-determination theory (Deci\& Ryan, 1985), Competence motivation theory, (Harter, 1981) achievement goal theories, (Nicholls, 1984) social exchange theory (Thibaut\& Kelly, 1959) and social learning theory (Bandura, 1971).This study was hankered in the social learning theory to underpin the social influences of male volleyball players in Kenya.

Social learning theories as propounded by Bandura (1971) postulates that behavior is learnt through role modeling and reinforcement from significant others.Banduras social learning theory demonstrates the effect of identity formation and learning through the observation of models as represented by significant others (Stroot,2002).However, the theory does not explain what happens after behavior has been learnt and internalized.This study was out to investigate the socialization process of volleyball male players in Kenya.This comes against a background of excellent performance of Kenyan women volleyball players at club and continental level.For example from 1990 to 1997 the African club championship title changed hands between two dominant female volleyball clubs of Nairobi Posta and Kenya Pipeline. Since then Kenyan women clubs such as Kenya Prisons,Kenya Commercial Bank have dominated the volleyball competitions in Africa .The national team for 
women volleyball (Queens of Africa) have not only won the continental championships several times but have represented Africa in the Olympic Games, world volleyball championships and the Grand Prix competitions.

It is apparent that few studies have been conducted in Africa on socialization into sports and their findings are quite diverse and inconclusive.For example ,Burnett (2005) examined the influences on the socialization of South African elite athletes $(n=123)$ and found the shifting nature and dominant role of significant others as socializing agents and the influence of environmental factors and socio-cultural and economic aspects.Gitonga,Bailasha and Toriola (2011)found that women volleyball players in Africa were influenced to play volleyball by family members and continued to play the game due to their success.Furthermore talent identification, enjoyment and social interactions were found to be the main motives for their continued participation.In a related study Mbaabu (1997) reported that elite female athletes in athletics viewed their peer group as both role models and sources of inspiration. Among Kenyan secondary school athletes, Rintaugu (2009) found that the role of significant others in socialization into sport is essentially by the coach, friends, Physical Education (PE) teachers, brothers, sisters and the mothers. Bailasha (1999) analyzed the serves used by teams which participated in the $12^{\text {th }}$ edition of feminine volleyball club championships and found that the floater serve was commonly used.This study focused on techno-tactical aspects of the game and did not address itself to social or psychological attributes of the players.Binboga,Kilic and Gokdemir (2013) examined the reasons why junior volleyball players start and continue playing volleyball and their expectations for future $(n=359)$ in Tukey. They found that the most reason was being a member of the national team and the motive for continuing to play is the love for the game.Papadopoulou,Fachantidou and Laloglou (2008) examined the social economic features of Greek national volleyball team $(\mathrm{n}=18)$ and found that female athletes' families never discouraged the girls from participating in sport and they were mainly secon-born children. Their family environment loved or had a special connection to sport. Does the same apply to their male counterparts. Thus the purpose of this study was to establish the male volleyball athletes, family background factors, reasons for specializing in volleyball and their reasons for continued participation in volleyball.

\subsection{Methodology}

\subsection{Study design and sample}

A descriptive survey design was used to collect data from 71 male participants who took part in the Kenyan Volleyball Federation (KVF) Division one league in the year 2015. The athletes mean age was $24.97+3.08$ years with a range of between 20 and 29 years. The league had 12 participating clubs (team) with an average of 15 players per team resulting into a target population of 180 participants. Most of the above teams are based in Nairobi City County and the questionnaire was administered to 10 teams in Nairobi.However, some two teams did not take part in the study as their performance in the league was dismal and team management could not allow access to the players. Consequently, it's the data of 71 participants which is presented in subsequent sections.Most of the participants $38(53.50 \%)$ had experiences in competitive volleyball of 1 to 3 years followed by those with experiences of 5 to 6 years. Those with experiences of 7 to 9 years were 5(7.04\%) while those with experiences of over 10 years were $8(11.27 \%)$.

\subsection{Instrumentation}

A self-report questionnaire was utilized for data collection. The questionnaire which had two sections had been utilized in previous studies (Burnet, 2005; Gitonga et al.,2011; Rintaugu et al.,2014).Section A of the questionnaire had items seeking the participants bio data of age, parental SES, nature of family playing experience while section $B$ raised sport-specific issues revolving around influence of significant others, reasons for specializing in volleyball and motives for continued participation. These required categorical responsesof "Yes" and "No". The questionnaires were administered to the athletes during their training sessions with the assistance of coaches and team managers. This was done after obtaining informed consent from the athletes according to established guidelines (Thomas, Nelson \& Silverman, 2011). Subsequent data collected was analyzed for frequencies and reported in percentages.

\section{Results}

The players' biological brothers and sisters are presented in Table 1 while their motives for partici[ation in Volleyball are presented in Table 2. 
Table 1: Biological Brothers and Sisters Older and YoungerThan You(n=71)

\begin{tabular}{|l|l|l|l|l|}
\hline Brothers & Older & Younger \\
\hline Number & F & \% & F & \% \\
\hline 0 & 8 & 11.28 & 18 & 25.35 \\
\hline 1 & 27 & 38.03 & 23 & 32.39 \\
\hline 3 & 19 & 26.76 & 14 & 19.72 \\
\hline 3 & 6 & 8.45 & & \\
\hline 4 & 8 & 11.28 & 9 & 12.68 \\
\hline 4 & 3 & 4.23 & 7 & 9.86 \\
\hline
\end{tabular}

\section{Sisters}

\begin{tabular}{|l|l|l|l|l|}
\hline Number & Older & Younger \\
\hline Sisters & F & \% & F & \% \\
\hline 0 & 11 & 15.49 & 16 & 22.53 \\
\hline 1 & 35 & 42.29 & 22 & 30.98 \\
\hline 2 & 12 & 16.90 & 29 & 40.84 \\
\hline 3 & - & - & 4 & 5.63 \\
\hline 4 & 9 & 12.68 & & \\
\hline 4 & 4 & 5.63 & & \\
\hline
\end{tabular}

The results in Table 1 show that 27(38.03\%) of the athletes had one older brother followed by those with two older brothers 19(26.76\%).In regard to younger brothers, $23(32.39 \%)$ had one younger brother followed by $18(25.35 \%)$ who did not have a younger brother.35(42.29\%) of the athletes had one older sister followed by those who did not have younger sisters $29(40.84 \%)$ and those who had one younger sister at $22(30.98 \%)$ and no younger sisters $16(22.53 \%)$.

Table 2:Volleyball athletes' parental social economic status based on level of education and $\operatorname{occupation}(\mathbf{n}=71)$

\begin{tabular}{|l|l|l|l|l|}
\hline & Father & Mother \\
\hline Level of Education & F & \% & F & \% \\
\hline No formal Education & 2 & 2.81 & 6 & 8.45 \\
\hline Primary school & 3 & 4.23 & 7 & 9.86 \\
\hline Secondary & 12 & 16.90 & 11 & 15.49 \\
\hline Middle level & 37 & 52.11 & 29 & 40.84 \\
\hline University & 20 & 32.94 & 16 & 25.35 \\
\hline
\end{tabular}

\begin{tabular}{|l|l|l|l|l|}
\hline Occupation & & & & \\
\hline Professional & 34 & 47.89 & 20 & 28.16 \\
\hline Managerial & 8 & 11.27 & 9 & 12.67 \\
\hline Skilled & 4 & 5.63 & 1 & \\
\hline Commercial/Business & 9 & 12.68 & 15 & 21.13 \\
\hline Teaching & 4 & 5.63 & & \\
\hline Unskilled & 2 & 2.81 & 4 & 5.63 \\
\hline Teaching & 8 & 11.27 & 11 & 15.49 \\
\hline Forwarding & 2 & 2.81 & & \\
\hline Health workers & - & & 5 & 7.04 \\
\hline House wife & - & & 7 & 9.85 \\
\hline
\end{tabular}

The athletes parental level of education reveals that most of the athletes had their fathers and mothers having attained secondary education $37(52.11 \%)$ and $29(40.84 \%)$ for fathers and mothers respectively. These were followed by those athletes whose Parents had middle level college education (fathers 20(32.94\%) and mothers $16(25.35 \%)$. Athletes fathers and mothers with university education were $12(32-94 \%)$ and $11(15.49 \%)$ respectively.In regard to the athletes' parental occupation, most of the fathers and mothers $34(47.89 \%)$ and $20(28.16 \%)$ were in skilled occupations. Those in skilled were followed by those in commercial/business $9(12.68 \%)$ and for mothers in commercial/business were 15(21.13\%). The motives for participation in volleyball of the players are presented in Table 3. 
Table 3: Motives for Participation in Volleyball $(n=71)$

\begin{tabular}{|l|l|l|l|l|}
\hline Motives & Yes & $\mathbf{\%}$ & No & \% \\
\hline Health, finances or body aesthetics & 52 & 73.24 & 19 & 26.76 \\
\hline Psychological well-being & 68 & 95.78 & 3 & 4.22 \\
\hline Possibility of achievement and success & 68 & 95.78 & 3 & 4.22 \\
\hline Felt talented & 71 & 100 & & \\
\hline Enjoyment & 71 & 100 & & \\
\hline Possibility of external rewards & 65 & 91.55 & 6 & 8.45 \\
\hline Influence of my parents/family & 50 & 70.42 & 21 & 29.58 \\
\hline Influence of my friends & 59 & 83.09 & 12 & 16.90 \\
\hline Influence of my teachers & 55 & 77.46 & 16 & 22.54 \\
\hline Influence of Coaches & 60 & 84.51 & 11 & 15.49 \\
\hline Influence of mass media & 64 & 90.14 & 07 & 9.86 \\
\hline Social status of sport & 66 & 92.96 & 05 & 7.04 \\
\hline Influence of mass media & 54 & 76.06 & 17 & 23.9 \\
\hline Social interactions & 71 & 100 & & \\
\hline Availability of facilities equipment & 58 & 81.69 & 13 & 18.31 \\
\hline
\end{tabular}

The athletes initial interest and entry in playing volleyball was spurred by the highest valued motives of talent, enjoyment, social interactions, psychological well-being and possibility of achievement and success. The least ranked arousals were influence of media, teachers, availability of facilities/equipment, health and influence of parents and family members. The reasons for the athletes'continued participation in volleyball is presented in Table 4.

Table 4: Reasons for Continued Participation in Volleyball $(n=71)$

\begin{tabular}{|l|l|l|l|}
\hline Reason & Yes & No \\
\hline & F & \% & \\
\hline Success in Sport & 71 & 100 & \\
\hline Financial rewards & 62 & 87.32 & 9 \\
\hline Career opportunities & 65 & 91.55 & 6 \\
\hline Travel opportunities & 66 & 92.96 & 5 \\
\hline Recognition & 66 & 92.96 & 5 \\
\hline Status/prestige & 65 & 91.55 & 6 \\
\hline Talent & 71 & 100 & \\
\hline Desire to win & 71 & 100 & \\
\hline Personal development & 68 & 95.55 & 4.22 \\
\hline Self-actualization & 67 & 94.37 & 5.63 \\
\hline Religious beliefs & 33 & 46.48 & 52.52 \\
\hline Possibility of employment & 63 & 88.73 & 11.27 \\
\hline
\end{tabular}

Their reasons for continued participation in volleyball were talent, desire to win, success,personal development, self-actualization, travel opportunities and recognition. On the reverse the least involved reasons for continued participation in volleyball were religious beliefs financial rewards, possibility of employment and status/prestige. The influence of significant others on the volleyball players is presented in Table 5 .

Table 5: Influence of Significant others in Volleyball $(n=71)$

\begin{tabular}{|l|l|l|l|l|l|l|}
\hline Significant others & Positive & \multicolumn{3}{|c|}{ Negative } & \multicolumn{2}{l|}{ No influence } \\
\hline Family members & F & $\mathbf{\%}$ & F & \% & F & \% \\
\hline Spouse/boyfriend & 68 & 95.78 & 3 & 4.22 & & \\
\hline Coach & 61 & 85.92 & 7 & 9.86 & 3 & 4.23 \\
\hline Teachers/lectures & 68 & 95.78 & 3 & 4.22 & & \\
\hline Fiends/peers & 63 & 88.73 & 3 & 4.22 & 5 & 7.04 \\
\hline Teammates & 71 & 100 & & & & \\
\hline Yourself & 71 & 100 & & & & \\
\hline Employers & 71 & 100 & & & & \\
\hline
\end{tabular}

As athletes continue to participate in volleyball the role of significant others (those closely associated with them) is crucial.Based on the results in Table 5 show that volleyball athletes continue to be influenced mainly by friends/peers, teammates, themselves, coach and family members. The significant others with minimal influence are spouses/girls friends, teachers and employers. 


\section{Discussion}

The purpose of this study was to find out the volleyball players' parental social economic status ,motives for participation,reasons for continued participation and the influence of significant others.Findings indicate that over $50 \%$ of the athletes had playing experiences in competitive volleyball of over 6 years. These findings are comparable to Papadopoulou et al. (2008) where members of the Greek national team played competitive volleyball for the national team for $4.7+2.6$ years This shows that athletes in volleyball can play competitively for a long period of time. This could be attributed to the fact that volleyball is a non-contact sport and consequently injuries which lead to early career termination are not there or are minimal. These findings are in consonance with reported in other studies (Ahmed,2015)

Athletes in this study came from families where they had older and younger siblings. These findings are supported in Singh (2000) and Gitonga et al., (2011) that for female athletes second born athletes were motivated by the family to participate in sport. Literature indicates that it is possible to get influenced into taking part in sport of other family members are involved (Akpata \& Gitonga,2002 ;Rintaugu, 2005).Birth order impact on the social world of athletes in the sense that first borns are relatively more dependent on older siblings for support in their sport roles(Ebiharu et al.,1983)

Athletes parental levels of education had majority having secondary education. These findings are consonance with those of Ahmed (2015) where $83 \%$ of interuniversity men volleyball players belong to the middle and lower economic strata.Similarly ,Otieno et al.,(2020 had reported that most of the parents of rugby palyers in Kenya had secondary education.Parents mainly transmit the orientation and ideology of upward social mobility through successful sport participation to children especially in poorer sections of society (Burnett,2005). Whereas it is difficult to attribute athletes' parental education to prowess in volleyball, it can be postulated that volleyball is a common man's game in terms of exposure and the needed sports infrastructure. This is also supported in the athletes' parental occupation of skilled, commercial/business and teaching, hitherto volleyball is a very popular sport in low and middle cost secondary schools.It is a game that is competed aggressively in primary schools. Consequently, it can be postulated that the athletes may have started taking part while enrolled in local primary and secondary schools. Secondly, it is possible that the parents based on their education level and occupation could not afford to socialize their sons in costly sports like tennis, basketball, hockey and rugby.

Findings reveal that the motives which spurred interest in volleyball for those athletes were talent, enjoyment, social interactions, psychological well-being and possibility of achievement and success. The possible reason is that volleyball like all other sports once learnt can be contagious besides volleyball in Kenya has not penetrated to the proffessionla level of play. These reasons are cross-cutting and find refuge in the theories of self-determination social learning and competence motivation theories. These reasons have also been reported elsewhere (Gitonga, et al., 2011; Burnett, 2005; Rintaugu et al., 2014). It's the athletes personal goals and perceptions of potential success that inform the athletic identity which impacts positively on the continuation of a sporting career (Stroot,2002).For example, Rintaugu et al., (2014) reported that athletes in their study started participating in their specific sport due to enjoyment, talent achievement and psychological well-being. Once athletes discover that they are talented, then they strive to achieve success in competitions.Kotnik et al (2012) found that the motives for participating in sport was competition and winning

Conversely, the least ranked reasons for entry into volleyball were the influence of media, teachers, availability of facilities / equipment, health and influence of parents/family. While such motives hve been reported elsewhere ,the possibility of these motives to be rated least in Volleyball could be attributed to the nature of modern family where the social environment of players is opened tho the wider community at a very early age. These reasons are in agreement with findings by Gitonga et al., (2011)contrary to what is expected in sociological literature. For instance, it is true that parents/family and teachers are pivotal in socialization into sport but the results are just contrary (Rintaugu, 2005). Secondly, lack of influence of the media is not remote as volleyball in Kenya is only popular in the rural areas where media is beyond reach of the many young boys and girls. The lack of influence of teachers at the initial stages is attributed to the Kenyan education system whose primary objective is passing examinations and little emphasis is placed in participation in co-curricular activities.

The positive experiences and success in competitions are carried over into the second phase of specialisation in a sport(Prus \& Irine,1980).The athletes reasons for continued participation in volleyball are talent, desire to win, success, personal development, travel opportunities and recognition. These reasons are both intrinsic and extrinsic in nature but they are tilted towards intrinsic motives. These reasons have been reported elsewhere (Johansson, 1992; Weiss, 2001). Johansson (1992) and Weiss (2001) opined that travelling and gaining expertise are external rewards as well as internal rewards in terms of personal development, self-actualization and self-belief are recognized as least important reasons for continued specialization into a sport.

The role of significant others cannot be ignored in the context of continued volleyball participation and competition. This is essential as the athletes require encouragement, social support, rewards and sharing obligations as they continue to seek excellence. As expected in the social learning theories, socialization is a multistage process and the primary agents(Cote ,1999;Deci \&Eccles ,2004 :Fredricks \& Eccles,2004) are replaced by 
secondary agents such as teachers, peers, coaches and spouses (Malina,1994). Athletes in this study continue to be influenced overtly by friends/peers teammates and the coach.This is consistent with assertions that friends and peers encourage sport participation among boys and girls in secondary schools (Kubayi et al.,2014) Stevenson (1990) opined that athletes introduction to the sports in which they eventually gained international status were sponsored by a variety of of individuals such as parents,siblings,peers and others. Other contingencies had to occur before they became committed to sport and those included potential fo success and the people involved in sport.Prus (1984) had described sponsored recruitment as others willing to support the athletes involvement in sport or providing opportunities that encourage the athletes involvement.

It is regrettable that the employees has minimal influence over the athletes in this study yet a majority of the volleyball clubs in Kenya are supported by corporate organizations. It can only be speculated that the athletes may not be uncomfortable with the remuneration coming from their employers and there is need for more input from the employer.

\section{Conclusions}

It is concluded that athletes entered into volleyball due to diverse intrinsic and extrinsic reasons. Their continued participation is attributed to essentially extrinsic reasons and the secondary agents significant others combine to influence their continued participation in volleyball.However school environment seem to be a base in which volleyball players are founded.Majority of players feel that playing volleyball to express is qiute gratifying no wonder it is possible to find coporate teams having volleyball players who are not part of the employees.

\section{Recommendations}

As socialization into volleyball is a continuous process, then those associated with the volleyball athletes should take stock of their motives. More aptly there is need for team managers to vary the reinforcement mechanisms which have been put in place.Secondly, the corporate world (supporters) of the volleyball clubs need to improve on their relationships with the athletes. They can also devise ways of turning volleyball into a proffessional sport in Kenya.Since talent is reported as the main reason for playing volleyball a well thought out talent identificationand nurturing system should be developed at the lowest level of child growth.Parental guidance is also important in influencing the players choice of sport.Future studies need to unearth the challenges of playing competitive volleyball in Kenya and also establish whether the motives for initial entry and continued participation are nfluenced by other factors such as educational level of the athletes and their need to come up with a structured reward structure for the volleyball athletes in Kenya.

\section{References}

Ahmed, Q.B. (2015). Social Economic Status of Interuniversity Volleyball Players. International Education EJournal, 4, 4:21-26.

Akpata, D.O. \& Gitonga, E.R. (2002). Social economic status of secondary school interscholastic athletes in Nairobi Province, Kenya. Journal of International Council for Physical Education Recreation, Sports and Dance, 353(2), 28-30.

Bailasha ,N.K. (1999).The effectiveness of serves used during the 12 th edition of the African volleyball club championships.Unpublished Med Thesis,Kenyattauniversity,Nairobi,Kenya.

Bandura, A. (1971). Social learning theory. Eagle Wood: Prentice Hall.

Binboga, M., Kilic, I. \& Gokdemir, K. (2013). Motive of Junior Volleyball Players to Start and Continue Volleyball and their Expectations for Future. Journal of Sport and Performances, 4 (2): 29-39.

Burnett, C. (2005). Influences on socialization of South African elite athletes. South African Journal for Research, Physical Education and Recreation, 27(1), 37-50.

Coakley, J.J. (2005). Sport and Society: Issues and Controversies, St. Louis, Mosby.

Cote,J. (1999). The influence of Family in the development of Talent in Sport. The sports Psychologist, 13 (4): $395-417$.

Deci, E.L. \& Eccles, J.S. (2004). Parental influences on youth involvement in Sports. In M.R. Weiss (Ed). Development Psychology, lifespan Perspective, Morgantown, Fitness Information Technology.

Deci ,E.L. \& Ryan ,R.M.(1985).Intrinsic Motivation and Self Determination in Human Behavior.New York :Plenum.

Ebihara,O.,Ikeda,M. \&Myiashita,M.(1983).Birth order and children socialization into sport.International Review for the Sociology of Sport (IRSS) 18(3):69-90.

Fredricks, J.A. \&Eccle, J.S. (2004). Parental influences on youth involvement in sports. In M.R. Weiss (ED). Development Psychology, Lifespan Perspective, Morgantown, fitness information technology.

Gitonga, E., Bailasha, N.K. \&Toriola, A.L. (2011). Psycho-social attributes of elite women volleyball players. African Journal of Physical Health Education Recreation and Dance (AJPHERD), 17(3), 535-547.

Harter, S. (1981). The development of competence motivation in the Mastery of cognitive and physical skills. Is 
there still a place for joy? In G.C. Robert \& D.M., Landers(Eds) Psychology of Motive Behavior and Sport (Pp 3-29). Champaign, LL:Human Kinetics.

Ipinmoroti, O.S. \&Ajayi, M.A. (2003). Effects of motivation of significant others on sport involvement of athletes in Nigerian tertiary institutions. Journal of International Council for Physical Education Recreation, Sports and Dance,(ICHPER-SD) XL, 4, 28-36.

Johanson, J.D. (1992). Social aspects of sports participation of Swedish athletes with disabilities: pilot study. Unpublished Master's Thesis, Pullman, USA: Washington State University.

Kotric, B., Leskosek, B. \& Topic, M.D. (2012). Sport Identity of Volleyball players: An Intercultural Comparison. Kinesiological Slovenia, 18 (1) 38 - 52.

Kubayi ,N.A.,Jooste ,J.,Toriola ,A.L. \& Paul,Y.(2014).Familial and peer influences on sport participation among adolescents in rural south African secondary schools.Meditteranean Journal of Social Sciences,5(20):13051309.

Malina, R.M. (1994). Physical Activity and Training: Effects on Stature and Adolescent Growth in Sport. Medicine and Science in Sport and Exercise, 26, $759-766$.

Mbaabu, S.M. (1997). An investigation into psychological factors affecting Kenya'sWomen's performance in international truck events. Unpublished MEd Thesis ,Kenyatta University Nairobi, Kenya.

Mcpherson, B.D., Curtis, J.E. \& Loy, J.W. (1989). The social Significance of Sport: An introduction to the Sociology of Sports. Champaign: Human Kinetics.

Nicholl, J.G.(1984). Achievement motivation: conceptions of ability subjective experience, task choice and performance. Psychological Review, 91:328-346.

Otieno, M. D., Bailasha,N. K. \& Rintaugu, E. G.(2020): Influence of peer interaction through peer components on talent identification for players in rugby clubs in Kenya. International Journal of Research and Innovation in Social Sciences , 5.5:178-183.

Papadopoulou, S.D., Papadopoulou, S.K., Fachantidou, A. \&Laloglou, A. (2008). The social economic profile of Greek Women's National Volleyball Team. Women in sport and Physical Activity Journal, 17 (2): 50-61.

Philips, J.C.(1993). Sociology of Sport. Boston, MA: ALLYA and Bacon.

Prus,R. \&Irine,S.(1980).Hookers, rounders and desk clerks. Toronto :Cage.

Prus,R.(1984).Career Contigencies :Examining patterns of involvement.In N.Therberge \& P.Donnely (ed).Sport and the Sociological Imagination (pp 297-317).Fort Worth ,TX:TCU Press.

Rintaugu, E.G. (2005).Socialization into sport of secondary school athletes in Kenya. UnpublishedPh.D thesis, Kenyatta University, Nairobi, Kenya.

Rintaugu, E.G.(2009). Significant others influence on socialization into sport of Kenyan Secondary School athletes.Journal of Educational Research and Development ,4(1): 111-117.

Rintaugu, E.G.,Kamande, I.M., Litaba, S.A., Toriola, A.L. \&Amusa, L.O., (2014). Correlates of motivational orientation among Kenyan University athletes. African Journal of Physical Health Education Recreation and Dance(AJPHERD), 20(3:1), 1049 - 1064.

Singh, K.J. (2000). Birth Order and Female Sport Involvment. Congress on sport science, sports medicine and physical education (pp 28 - 29). Brisbane, Australia: Sport Medicine, Australia.

Stevenson, C.L. (1990). The early careers of International athletes. Sociology of Sport Journal, 7(3):238-253.

Stroot,S.A. (2002).Socialisation and participation in sport.InA.Laker (ed).The Sociology of Sport and Physical Education (129-147).London, Routledge,Falmer.

Thibaut, J.W. \& Kelly, H.H.(1959). The Social Psychology of Groups; New York:Wiley.

Thomas, J.R., Nelson, J.K. \& Silverman, S.J (2011). Research Methods in Physical Activity (6 ${ }^{\text {th }}$ ed.). Champaign, IL: Human Kinetics.

Wamukoya, E.K. (1993). An evaluation of the physical education in Secondary Schools in Kenya. Unpublished PhD Thesis, Manchester University, Manchester, U.K.

Weiss, D.S. (2001). Identity reinforcement in sport: Revisiting the symbolic interactions' legacy. International Review for the Sociology of Sport, 36(4), 393-405 